October 2014

\title{
Association between sella turcica bridging and palatal canine impaction
}

Batool A. Haider

Attiya Shaikh

Mubassar Fida

Follow this and additional works at: https://ecommons.aku.edu/

pakistan_fhs_mc_surg_dent_oral_maxillofac 


\title{
Association between sella turcica bridging and palatal canine impaction
}

\author{
Batool Ali, ${ }^{\text {a }}$ Attiya Shaikh, ${ }^{\text {b }}$ and Mubassar Fida ${ }^{\mathrm{c}}$ \\ Karachi, Pakistan
}

\begin{abstract}
Introduction: The association of sella turcica bridging and various dental anomalies has been an area of interest for researchers. Based on the evidence of a common embryologic origin between sella turcica and the teeth, the objectives of this study were to measure the dimensions of sella turcica and to test whether an association exists between sella bridging and impacted canines. Methods: Orthodontic records comprising standard-quality lateral cephalograms and dental panoramic radiographs were selected. Thirty-one patients with palatally impacted canines (20 female, 11 male; mean age, $18.4 \pm 8.9$ years) and 70 controls with erupted canines (35 male, 35 female; mean age, $17.1 \pm 7.5$ years) were included in the study. Comparison of sella dimensions between the patients and the controls was carried out by independent sample $t$ tests, whereas the association of sella bridging with impacted canines was analyzed using the chi-square test. Results: The frequencies of complete and partial calcification of sella in the patients were $8(25.8 \%)$ and $17(54.8 \%)$, respectively, whereas those in the controls were 0 and $36(51.4 \%)$, respectively. The frequency of sella bridging was significantly higher in subjects with canine impaction than in the controls $(P<0.001)$. The sagittal interclinoidal distance was found to be significantly reduced in the patients $(P=0.028)$. According to the statistical analysis, age and sex do not influence the dimensions and calcification of sella turcica. Conclusions: Sella bridging is frequently found in patients with impacted canines. Hence, sella bridging can complement other diagnostic parameters in confirming the status of canine impaction. (Am J Orthod Dentofacial Orthop 2014;146:437-41)
\end{abstract}

$\mathrm{M}$ axillary canine impaction is a dental anomaly found in $1 \%$ to $2 \%$ of clinical situations, with a higher prevalence rate in female patients. ${ }^{1}$ The etiology of this anomaly is diversified with underlying local, systemic, and genetic factors. Common theories contributing to the etiology of maxillary canine impaction are guidance theory and the genetic theory. ${ }^{2,3}$ According to the genetic theory, impacted maxillary canines are conjointly associated with other genetic abnormalities such as submerged deciduous molars, hypoplastic enamel, mandibular premolar aplasia, and diminutive maxillary lateral incisors. ${ }^{3,4}$ Early detection and timely intervention of impacted canines can

From Aga Khan University Hospital, Karachi, Pakistan.

${ }^{a}$ Resident, Department of Orthodontics, Section of Dentistry, Department of Surgery.

${ }^{\mathrm{b}}$ Consultant orthodontist, assistant professor, and program coordinator of the orthodontics residency program, Section of Dentistry, Department of Surgery. c Consultant orthodontist, associate professor, and program director of the orthodontics residency program, Section of Dentistry, Department of Surgery. All authors have completed and submitted the ICMJE Form for Disclosure of Potential Conflicts of Interest, and none were reported.

Address correspondence to: Attiya Shaikh, Orthodontics Residency Program, Section of Dentistry, Department of Surgery, Aga Khan University Hospital, PO Box3500, Stadium Rd, Karachi 74800, Pakistan; e-mail, attiya.shaikh@aku.edu. Submitted, February 2014; revised and accepted, June 2014.

0889-5406/\$36.00

Copyright (C) 2014 by the American Association of Orthodontists.

http://dx.doi.org/10.1016/j.ajodo.2014.06.010 reduce the time, expense, and complexity of treatment in the permanent dentition. Conventional 2dimensional and 3-dimensional imaging is routinely used in diagnosing the position and the expected path of eruption of the permanent canines. These radiographs are also a diagnostic tool in detecting skeletal variations related to the skull and cervical spine, including abnormal sella turcica morphology, a sella bridge, or fusion of the cervical vertebrae occurring with craniofacial and dental deviations. ${ }^{5,6}$

Sella turcica has a major importance in the field of orthodontics. The anterior contour of sella turcica is useful in predicting patient growth and in assessing the craniofacial morphology and superimposing serial cephalograms. ${ }^{7}$ Orthodontists should be familiar with the morphologic variations of sella turcica that will aid in diagnosing any underlying pathologies associated with it. One common morphologic variation of sella turcica is the sella bridge. Exaggerated ossification of the dura mater between the anterior and posterior clinoidal processes of the sphenoid bone or abnormal embryologic development of the sphenoid bone results in this irregular bridge formation. ${ }^{8-10}$ Hence, the sella bridge can be treated as a developmental anomaly.

In healthy persons, the frequency of sella bridging ranges from $1.1 \%$ to $13 \% .^{11,12}$ The dimensions of sella 
turcica vary from 5 to $16 \mathrm{~mm}$ in the anteroposterior diameter and from 4 to $16 \mathrm{~mm}$ for the vertical depth. ${ }^{13,14}$ Until lately, studies have linked the sella turcica bridge to multiple hereditary developmental syndromes affecting the craniofacial region and various systemic disorders. ${ }^{15-20}$ it has also been discovered that many local dental anomalies such as tooth transposition, hypodontia, and missing mandibular second premolars have associations with interclinoidal calcification. $^{21,22}$

A survey of the pertinent literature has shown that only limited data are available on this topic; even though the dimensions of sella turcica have a significant impact on interclinoidal calcification, there has only been 1 study in this area. ${ }^{23}$ Since sella bridging is considered as a developmental and genetic anomaly, variations in the genetic makeup of different populations might lead to different results. Hence, to establish authentic results, the findings of previous studies need to be replicated in different populations with varying racial backgrounds.

The aims of our study were to compare the dimensions of sella turcica in Pakistani orthodontic patients with impacted vs erupted canines and to test whether an association exists between sella turcica bridging and canine impaction.

\section{MATERIAL AND METHODS}

Pretreatment records of 35 subjects with impacted canines were collected retrospectively after screening the records of 707 Pakistani orthodontic patients visiting the dental clinics in the last 5 years. Inclusion of subjects in the study was based on good-quality standardized lateral cephalograms with a clear reproduction of sella turcica. Impacted canines were diagnosed on the basis of dental panoramic radiographs, whereas the buccopalatal position was diagnosed using the vertical parallax technique (dental panoramic radiograph and anterior occlusal radiograph). ${ }^{24,25}$ of the 35 subjects, 31 had palatal impactions, and 4 had buccally impacted canines. Those with buccal impactions were excluded, and the study was conducted on a sample of 31 patients ( 11 male, 20 female; ages, 14-30 years; mean age, $18.9 \pm 8.9$ years) with maxillary palatal canine impactions. Subjects with cleft lip and palate, craniofacial anomalies and syndromes, trauma, or previous orthodontic treatment were excluded from the study.

The control group consisted of 70 subjects ( 35 male, 35 female; ages, $15-33$ years; mean age, $17.1 \pm 7.5$ years) with normally erupted canines. This group was randomly selected from the orthodontic records of 707

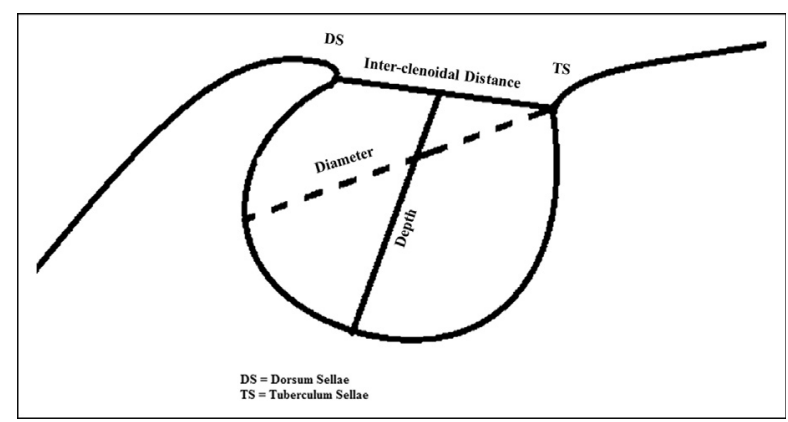

Fig. Linear dimensions of sella turcica (interclinoidal distance, sella depth, and sella diameter).

patients who visited the dental clinics in last 5 years. The exclusion criteria of the controls were similar to those of the subjects.

The post hoc analysis showed that this sample size achieved a statistical power of 0.82 for detecting a clinically significant difference greater than $25 \%$ in sella bridging between the subjects and the controls.

Cephalograms were traced manually on acetate sheets with a $0.5-\mathrm{mm}$ lead pencil in a dark room with conventional methods. Sella turcica was drawn as a U-shaped structure from the tip of the dorsum sellae to that of the tuberculum sellae as seen on the radiograph. The linear dimensions shown in the Figure were measured as follows.

1. Interclinoidal distance: distance from the tip of the dorsum sellae to that of the tuberculum sellae.

2. Depth of sella turcica: distance of a line dropped perpendicular from the line above to the deepest point on the sella floor.

3. Anteroposterior diameter of sella turcica: distance from the tip of the tuberculum sellae to the farthest point on the inner wall of the hypophyseal fossa.

To evaluate and quantify the level of bridging, the standard scoring scale developed by Leonardi et $\mathrm{al}^{21}$ was used. On the basis of sella dimensions, the bridging was classified into 3 groups.

1. No calcification: this was rated as type 1 , where the length was either equal to or greater than three fourths of the diameter.

2. Partial calcification: this was rated as type 11 , where the length was equal to or less than three fourths of the diameter.

3. Complete calcification: this was rated as type 111 , where only the diaphragm sellae was visible on the radiograph.

To determine the intraexaminer agreement in the identification of the sella turcica bridge, 30 randomly 
selected lateral cephalometric radiographs were retraced and reevaluated by the principal investigator (B.A.) 2 weeks after the initial analysis. The kappa coefficient value was 0.83 , showing a substantial strength of agreement. ${ }^{26}$

SPSS software for Windows (version 19.0; SPSS, Chicago, 111) was used for the statistical analysis of the data. The chi-square test was performed to test the degree of calcification in both groups. The strength of the association between sella bridging and impacted canines was estimated by calculating the odds ratio. Subjects with partial and complete bridging were grouped in 1 category, and logistic regression analysis was performed. The independent sample $t$ test was used to evaluate differences in the mean sella dimensions between the patients and the controls. $P \leq 0.05$ was considered statistically significant.

\section{RESULTS}

The mean dimensions of sella turcica in the subjects and the controls are shown in Table 1. Independent sample $t$ tests comparing the mean interclinoidal distances between the groups showed a reduced distance among the subjects with impacted canines $(P<0.012)$. The comparison of mean depths and diameters between the subjects and the controls was insignificant. The patient group was further analyzed for sex dimorphism, which showed no statistically significant difference in sella dimensions $(P>0.05)$ (Table 11).

The highest frequency of type 11 calcification was reported in 17 patients $(54.8 \%)$, whereas most subjects in the control group $(34 ; 48.6 \%)$ had type 1 calcification of sella ligaments. Type 111 calcification of the interclinoid ligament was observed in $8(25.8 \%)$ subjects with impacted canines, whereas no subjects had type 111 calcification in the control group (Table 111). Chi-square statistics were calculated for evaluating the degree of sella bridging in both groups, and the overall proportion of interclinoid ligament calcification differed significantly $(P<0.001)$. When we computed the degree of sella bridging between the sexes in the patients, no significant difference $(P<0.436)$ was noted (Table IV). The strength of the association between sella bridging and impacted canines was estimated by calculating the odds ratio. The odds of having partial and complete bridging among the patients was 3 to 4 times greater than in the control group (odds ratio, 3.93; 95\% Cl, 1.43-10.7).

\section{DISCUSSION}

In this study, we focused on the dimensions of sella turcica and the association of sella bridging in subjects
Table I. Comparison of sella dimensions $(\mathrm{mm})$ among subjects and controls

\begin{tabular}{lccc} 
& \multicolumn{3}{c}{ Sella dimensions (mean $\pm S D$ ) } \\
\cline { 2 - 4 } & $\begin{array}{c}\text { Sagittal } \\
\text { interclinoidal } \\
\text { distance }\end{array}$ & Sella depth & Sella diameter \\
Study group & $6.80 \pm 2.26$ & $7.96 \pm 1.18$ & $11.29 \pm 2.61$ \\
\hline Subjects $(\mathrm{n}=31)$ & $8.05 \pm 2.27$ & $8.25 \pm 1.63$ & $11.23 \pm 2.21$ \\
\hline Controls $(\mathrm{n}=70)$ & 8.012 & 0.146 & 0.608 \\
$P$ value $^{*}$ & 0.012 & \\
\hline *Independent sample $t$ test ${ }^{\dagger} P<0.05$.
\end{tabular}

Table II. Sella turcica measurements $(\mathrm{mm})$ in impacted canines (subjects) stratified by sex

\begin{tabular}{|c|c|c|c|}
\hline Sella measurements & Males $(n=11)$ & emales $(n=2$ & $\mathrm{P}$ value \\
\hline $\begin{array}{l}\text { Sagittal interclinoidal } \\
\text { distance }\end{array}$ & $7.22 \pm 2.84$ & $6.57 \pm 1.92$ & 0.200 \\
\hline Sella depth & $7.77 \pm 1.75$ & $8.07 \pm 1.36$ & 0.120 \\
\hline Sella diameter & $11.40 \pm 3.43$ & $11.22 \pm 2.14$ & 0.228 \\
\hline
\end{tabular}

with impacted vs erupted canines. These 2 parameters have not been previously studied in Pakistani orthodontic patients.

Altered morphology of the anterior wall of sella, anterior clinoidal process, and sella length plays a pivotal role in bridge formation. True bony union occurs at an early age, and insignificant changes are observed in sella length and sella bridge as a child matures. ${ }^{11}$ Moreover, the anterior part of sella turcica, the pituitary gland, and the dental epithelial progenitor cells share a common embryologic origin, which is the predominant derivative of neural crest cells. ${ }^{27}$ The sella turcica is the prime area for the migration of neural crest cells to maxillary, palatinal, and frontonasal developmental fields. ${ }^{20}$ In addition, mutations in the homeobox, HOX, or sonic hedgehog genes negatively influence the development of the midface, the teeth, and parts of sella turcica. ${ }^{28,29}$ According to the above theories, the canines and sella turcica share a common embryology; hence, alterations at the developmental level can result in a sella bridge that can simultaneously lead to impacted canines.

According to our study, the interclinoidal distance was reduced in patients with impacted canine, whereas sella depth and diameter showed no significant differences between the study groups. Our results agree with those of Najim and $\mathrm{Nakib}^{23}$ on an Iraqi sample with subjects ranging from 13 to 25 years. A study conducted on a sample of fixed orthodontic and surgical-orthodontic 
Table III. Degree of calcification in cases and controls

Sella Bridging, $n(\%)$

\begin{tabular}{lcccc}
\cline { 2 - 4 } Study groups & Type I & Type II & Type III & P value* \\
Subjects $(\mathrm{n}=31)$ & $6(9.67)$ & $17(54.8)$ & $8(25.8)$ & 0.000 \\
Controls $(\mathrm{n}=70)$ & $34(48.6)$ & $36(51.4)$ & $0(0)$ & \\
Type I, No calcification; Type & II, partial calcification; Type III, \\
complete calcification. & & & \\
$P \leq 0.05$. & & & \\
${ }^{*}$ Chi-square test; ${ }^{\dagger} P<0.001$.
\end{tabular}

Table IV. Sella bridging in the subjects

$\begin{array}{lccc}\text { Sella bridging } & \text { Males }(n=11) & \text { Females }(n=20) & \text { P value* } \\ \text { Type } 1 & 2 & 4 & \\ \text { Type } 11 & 7 & 10 & 0.436 \\ \text { Type III } & 2 & 6 & \end{array}$

Type I, No calcification; Type II, partial calcification; Type III, complete calcification.

$P<0.001$.

${ }^{*}$ Chi-square test.

patients showed a reduced sella length in the surgicalorthodontic group. ${ }^{30} \mathrm{~A}$ study of Pakistani subjects with different skeletal malocclusions found no correlation between the skeletal classes and sella dimensions. ${ }^{31}$ In our study, the size of sella with impacted canines was similar between the sexes. However, a longitudinal study conducted on the sizes and morphologies of Norwegian subjects reported an increased sella length in male subjects compared with female subjects, with no significant differences in depths and diameters. ${ }^{11}$ The results reported by Francis ${ }^{32}$ differed in this aspect; this author found larger sellae in female subjects. The difference in results might be due to ethnic and racial variations between the study populations.

The results of our study also demonstrated an increased frequency of sella bridging in patients with impacted canines. The $80.6 \%$ frequency of partial and complete bridging in our study compared favorably with the 70\% frequency reported by Najim and Nakib. ${ }^{23}$ The $25.8 \%$ frequency of complete calcification of sella in our study is higher than that reported by Leonardi et $\mathrm{al}^{6,21}$ who found complete sella bridges in only $16.7 \%$ and $18.4 \%$ of the subjects in their studies on palatally displaced canines. Similarly, studies reported incidences of $16.7 \%$ in patients undergoing combined surgical orthodontic treatment, ${ }^{30} 18.6 \%$ in patients with craniofacial deviations, ${ }^{33} 18.7 \%$ in patients with premolar aplasia, ${ }^{21}$ and $33.3 \%$ in patients with dental transpositions. ${ }^{22}$ In our study, no significant difference was found between the sexes; however, these results contrast with those of Najim and Nakib, ${ }^{23}$ who found an increase in sella bridging in male subjects compared with female subjects.

A review of the literature suggests that women have a higher prevalence of canine impactions than do men. ${ }^{1}$ In our study, sella bridging did not show a predilection for a particular sex, and the risk of canine impaction was therefore equal in both sexes. A strong association between sella bridging and palatally impacted canines suggests that factors affecting the development of sella turcica might also affect the development of the maxillary canines.

Thus, sella bridging highlights the risk of future palatal canine impactions, especially in children with a history of canine impaction in their parents or siblings and who are undergoing phase 1 orthodontic treatment. The results of our study suggest that careful monitoring is needed for the eruption timing of the maxillary canines in children diagnosed with complete calcification of sella turcica.

\section{CONCLUSIONS}

The following conclusions can be drawn from this study, which interrelates sella turcica bridging with impacted canines.

1. The frequency of sella turcica bridging is increased in patients with canine impactions.

2. Sella turcica length is reduced in patients with canine impactions.

3. Sex does not influence the size of sella and the ossification of the interclinoid ligament.

4. The chances of having partial or complete bridging in subjects with impacted canines are approximately 4 times greater than those with erupted canines.

\section{ACKNOWLEDGMENTS}

We thank Dr Waqar Jeelani for assistance in statistical analysis, and Dr Alefiyah Rajabali and Maria Rajabali for their help in language editing and proofreading the article.

\section{REFERENCES}

1. Bishara SE. Impacted maxillary canines: a review. Am J Orthod Dentofacial Orthop 1992;101:159-71.

2. Becker A, Smith P, Beher R. The incidence of anomalous maxillary lateral incisors in relation to palatally displaced cuspids. Angle Orthod 1981;51:24-9.

3. Peck S, Peck L, Kataja M. The palatally displaced canine as a dental anomaly of genetic origin. Angle Orthod 1994;64:249-56.

4. Baccetti T. A controlled study of associated dental anomalies. Angle Orthod 1998;68:267-74.

5. Sandham A. Cervical vertebral anomalies in cleft lip and palate. Cleft Palate J 1965;36:273-81. 
6. Leonardi R, Barbato E, Vichi M, Caltabiano M. Skeletal anomalies and normal variants in patients with palatally displaced canines. Angle Orthod 2009;79:727-32.

7. Bishara SE, Athanasiou AE. Cephalometric methods for assessment of dentofacial changes. 1n: Athanasiou AE, editor. Orthodontic cephalometry. London, United Kingdom: Mosby-Wolfe; 1995.

8. Dubrul EL. Oral anatomy. In: Sicher H, Dubrul EL, editors. The skull. Delhi, India: AITBS Publishers \& Distributor; 1996. pp 13.

9. Du Boulay G, Tricky S. The choice of radiological investigations in the management of tumors around the sella. Clin Radiol 1967;18: 349-65.

10. Skrzat J, Szewczyk R, Walocha J. The ossified interclinoid ligament. Folia Morphol 2006;65:242-5.

11. Axelsson S, Storhaug K, Kjær 1. Post-natal size and morphology of the sella turcica. Longitudinal cephalometric standards for Norwegians between 6 and 21 years of age. Eur J Orthod 2004;26: 597-604.

12. Alkofide EA. The shape and size of the sella turcica in skeletal Class 1, Class 11, and Class 111 Saudi subjects. Eur J Orthod 2007;29: 457-63.

13. Shapiro RS, Janzen AH. The normal skull. New York: Paul B. Hoeber; 1960.

14. Paul LW, Juhl JH. The essentials of roentgen interpretation. Hagerstown, MD: Harper and Row; 1972.

15. Axelsson S, Storhaug K, Kjær 1. Post-natal size and morphology of the sella turcica in Williams syndrome. Eur J Orthod 2004;26: 613-21.

16. Kimonis VE, Goldstein AM, Pastakia B, Yang ML, Kase R, DiGiovanna JJ, et al. Clinical manifestations in 105 persons with nevoid basal cell carcinoma syndrome. Am J Med Genet 1997; 69:299-308.

17. Kjær 1, Becktor KB, Lisson J, Gormsen C, Russell BG. Face, palate, and craniofacial morphology in patients with a solitary median maxillary central incisor. Eur J Orthod 2001;23:63-73.

18. Kjær 1, Hansen BF, Reintoft 1, Keeling JW. Pituitary gland and axial skeletal malformations in human fetuses with spina bifida. Eur J Pediatr Surg 1999;9:354-8.

19. Russell BG, Kjær 1. Postnatal structure of the sella turcica in Down syndrome. Am J Med Genet 1999;87:183-8.
20. Kjær 1. Sella turcica morphology and the pituitary gland-a new contribution to craniofacial diagnostics based on histology and neuroradiology. Eur J Orthod 2012 Nov 16 [Epub ahead of print].

21. Leonardi R, Barbato E, Vichi M, Caltabiano M. A sella turcica bridge in subjects with dental anomalies. Eur J Orthod 2006;28:580-5.

22. Leonardi R, Farella M, Cobourne MT. An association between sella turcica bridging and dental transposition. Eur J Orthod 2011;33: 461-5.

23. Najim AA, Nakib LA. A cephalometric study of sella turcica size and morphology among young lraqi normal population in comparison to patients with maxillary malposed canine. J Baghdad Coll Dent 2011;23:53-8.

24. Jacobs SG. Radiographic localization of unerupted maxillary anterior teeth using the vertical tube shift technique: the history and application of the method with some case reports. Am J Orthod Dentofacial Orthop 1999;116:415-23.

25. Jacobs SG. Radiographic localization of unerupted teeth: further findings about the vertical tube shift method and other localization techniques. Am J Orthod Dentofacial Orthop 2000;118:439-47.

26. Sim J, Wright CC. The kappa statistic in reliability studies: use, interpretation, and sample size requirements. Phys Ther 2005; 85:257-68.

27. Miletich 1, Sharpe PT. Neural crest contribution to mammalian tooth formation. Birth Defects Res C Embryo Today 2004;72:200-12.

28. Schoenwolf GC, Bleyl SB, Brauer PR, Francis-West PH. Larsen's human embryology. Philadelphia: Churchill Livingstone; 2009.

29. Duverger 0, Morasso M1. Role of homeobox genes in the patterning, specification and differentiation of ectodermal appendages in mammals. J Cell Physiol 2008;216:337-46.

30. Jones RM, Faqir A, Millett DT, Moos KF, McHugh S. Bridging and dimensions of sella turcica in subjects treated by surgicalorthodontic means or orthodontics only. Angle Orthod 2005;75: 714-8.

31. Shah AM, Bashir U, llyas T. The shape and size of the sella turcica in skeletal class 1, 11 \& 111 in patients presenting at 1slamic lnternational Dental Hospital, 1slamabad. Pak Oral Dent J 2011;31:104-10.

32. Francis CC. Growth of the human pituitary fossa. Hum Biol 1948; 20:1-20.

33. Becktor JP, Einersen S, Kjaer 1. A sella turcica bridge in subjects with craniofacial deviations. Eur J Orthod 2000;22:69-74. 